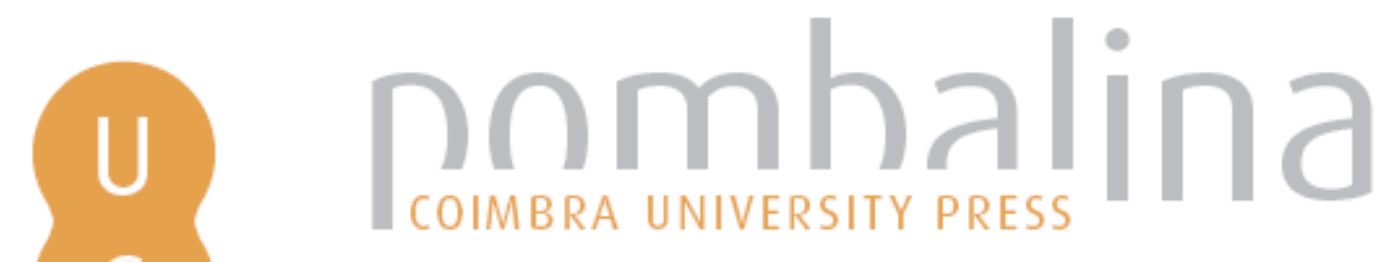

António Gama, um apaixonado pela Geografia e pelas mini rosas...

Autor(es): $\quad$ Souza, Maria Adélia de

Publicado por: Imprensa da Universidade de Coimbra

URL

persistente: URI:http://hdl.handle.net/10316.2/43475

DOI: $\quad$ DOl:https://doi.org/10.14195/978-989-26-1343-7_5

Accessed : $\quad$ 26-Apr-2023 08:09:52

A navegação consulta e descarregamento dos títulos inseridos nas Bibliotecas Digitais UC Digitalis, UC Pombalina e UC Impactum, pressupõem a aceitação plena e sem reservas dos Termos e Condições de Uso destas Bibliotecas Digitais, disponíveis em https://digitalis.uc.pt/pt-pt/termos.

Conforme exposto nos referidos Termos e Condições de Uso, o descarregamento de títulos de acesso restrito requer uma licença válida de autorização devendo o utilizador aceder ao(s) documento(s) a partir de um endereço de IP da instituição detentora da supramencionada licença.

Ao utilizador é apenas permitido o descarregamento para uso pessoal, pelo que o emprego do(s) título(s) descarregado(s) para outro fim, designadamente comercial, carece de autorização do respetivo autor ou editor da obra.

Na medida em que todas as obras da UC Digitalis se encontram protegidas pelo Código do Direito de Autor e Direitos Conexos e demais legislação aplicável, toda a cópia, parcial ou total, deste documento, nos casos em que é legalmente admitida, deverá conter ou fazer-se acompanhar por este aviso.

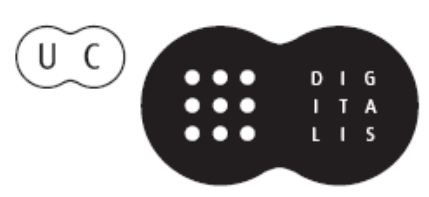




\section{FERNANDA CRAVIDÃO}

\section{IÚCIO CUNHA}

PAULA SANTANA

\section{NORBERTOSANTOS}

(ORG.)

\section{ESPAÇOS E TEMPOS EM GEOGRAFIA}

HOMENAGEM A ANTÓNIO GAMA

IMPRENISA DÁ UNIVERSIDADE DE COIMBRA COIMBRA UNIVERSITY PRESS

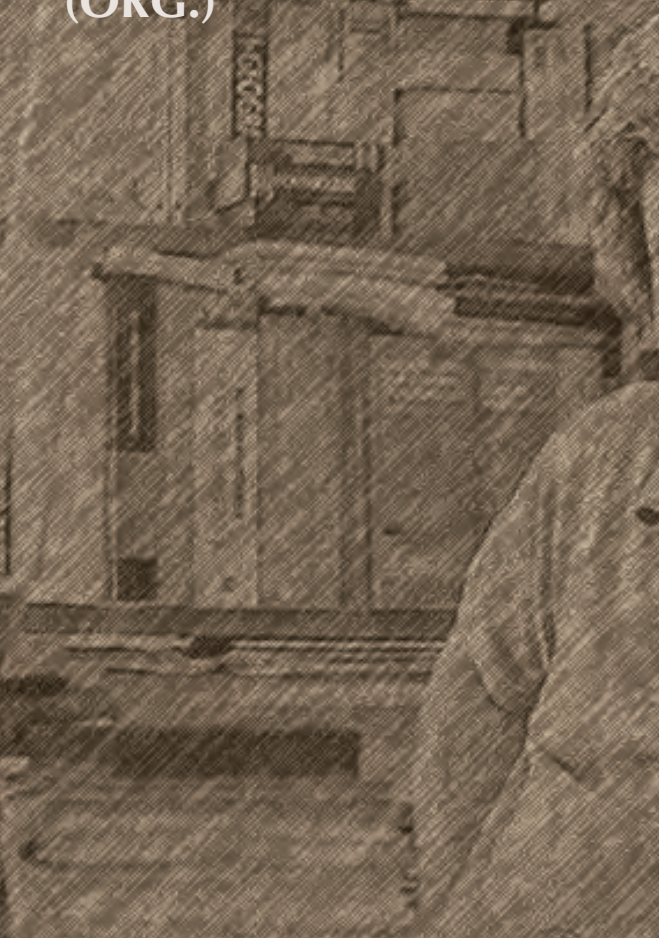




\title{
ANTÓNIO GAMA, UM APAIXONADO PELA GEOGRAFIA E PELAS MINI ROSAS...
}

\author{
Maria Adélia de Souza/madelia.territorial@gmail.com \\ Professora Titular de Geografia Humana da USP
}

Impressionou-me, profundamente, o conhecimento preciso e profundo de António Gama pela geografia portuguesa. Discreto, fala mansa, mas objetivo e valente na disputa pela palavra durante o trabalho de campo. Suas observaçóes sempre pertinentes, indicou-me tratar-se de um grande professor e pesquisador.

Atento às paisagens que se sucediam pelas janelas do ônibus onde nos encontrávamos, tanto comentava comigo que estava ao seu lado, quanto para os demais participantes dessa atividade, como um verdadeiro anatomista da paisagem: sua formação geológica com a geomorfologia decorrente, os processos de ocupação humana, mas encantava-se com as cidades e a urbanização portuguesas. Preocupava-se com a situação crítica pela qual passavam, dado o intenso e profundo processo de emigração que ocorre em Portugal, especialmente com o esvaziamento das aldeias que percorremos, lindas, sóbrias, mas vazias... revelando não apenas aí um conhecimento geográfico, mas também histórico, econômico, social e antropológico profundos.

Mas, sobretudo, revelava sua enorme sensibilidade como ser humano ao falar daquela gente que partira e dos velhos e crianças que permaneceram, vivendo no silêncio da aldeia esvaziada pelos desígnios da História da Europa de hoje... e de sempre! 
Foi assim que conheci Antônio Gama, no CEI - Centro de Estudos Ibéricos, na cidade da Guarda em junho de 2015, na fronteira com a Espanha!

Mas, embora tendo estado tão pouco tempo com Gama, como o chamava, percebi e senti nele uma preocupação com sua saúde.... Tinha uma rouquidão que parecia ter origem em uma rinite alérgica, ou algo que enchia seu pulmão de secreção e o incomodava enormemente...

Esse estado de saúde o incomodou durante todo o tempo em que pudemos falar durante o curso de verão do CEI e, sobretudo, durante o trabalho de campo.

Privilegio o meu estar ali, pois havia ido a Guarda participar da homenagem que prestavam naquele curso a outro mestre da Geografia e dos trabalhos de campo, meu colega Valentin Cabero, da universidade de Salamanca e, encontrar-me com Rui Jacinto e Lúcio Cunha, colegas geógrafos da universidade de Coimbra que eu havia conhecido em São Luís do Maranhão, algum tempo antes...

Encontro entre geógrafos que se tornaram amigos nessa bela defesa da lusofonia. Encontro de afetos, como era designada aquela reunião.

O tema desse curso já era apaixonante Espaços de Fronteira, Territórios de Esperança: velhos problemas, novas soluçóes, sobretudo para uma geógrafa brasileira que acabara de viver um ano e meio na tríplice fronteira Argentina, Brasil e Paraguai, ajudando a fundar a UNILA - Universidade da Integração Latino-americana.

Tudo convergia para que António Gama e eu conversássemos e debatêssemos muitas ideias durante toda a estadia na Guarda, pois nossos interesses eram bastante coincidentes e os problemas dos quais cuidávamos tanto na geografia quanto no planejamento eram por demais complexos para que se esgotassem rapidamente. Prometemos manter diálogos após minha volta ao Brasil, mas tristemente não houve tempo para tanto...

Tive o privilégio de ter a companhia de António Gama, no ônibus, logo no primeiro dia dos trabalhos de campo e, rapidamente, percebemos que nossos interesses pela geografia convergiam para a Epistemologia da Geografia, a Geografia Política e as questôes do Poder, o Planejamento Urbano e Regional e a importância do trabalho e observação em campo para o nosso "métier" de 
geógrafo. Mas foi na discussão sobre a complexidade e a imensidão das pesquisas a serem realizadas sobre a dimensáo cotidiana da vida na cidade que ocupou o pouquíssimo tempo que a vida nos ofereceu para conversar.

Indagou-me muito sobre a Geografia Nova que fazemos no Brasil e pude verificar o quanto, por outras vias e com pequeninas diferenças filosóficas, estávamos caminhando lado a lado!

Enquanto isso, no entanto, deslizávamos com nosso ônibus pela Raia Central de Portugal e Espanha, pano de fundo da XII Edição do Curso de Verão oferecido pelo CEI, com o sedutor título, como apontámos acima de "Espaços de Fronteira, Territórios de Esperança. Velhos problemas, novas soluçóes”.

Claro que em meio as interpretaçóes e leituras das paisagens que atravessávamos em nosso trabalho de campo, as conversas giravam em torno de nossas experiências como professores e pesquisadores de países assemelhados, próximos culturalmente, mas extremamente diferentes.

Gama, guardando a tradição da Geografia portuguesa, onde os aspectos físicos das paisagens são mencionados e considerados, e eu adepta que sou da Geografia Nova iniciada e proposta por Milton Santos, professor emérito da universidade de Coimbra, cujo esforço epistemológico histórico, de renovação da nossa disciplina lhe outorgou uma visibilidade pelo mundo todo.

Lamento que essa conversa apenas tenha se iniciado, pois ambos, pelo que senti das observaçóes de Antônio Gama somos apaixonados pela epistemologia da Geografia e todas as possibilidades que essa revisitação nos oferece para continuarmos a compreender as paisagens do mundo, mesmo deixando de lado o conceito de meio natural e acatando o meio técnico-científico informacional, como centro das nossas atençôes. Penso que essa conversa com Gama, se pudesse ter sido mais longa, me ajudaria em muito a caminhar no aperfeiçoamento da Geografia que Milton Santos nos deixou para continuar a aprimorar.

Foram dias de debates interessantes e profundos sobre uma realidade que eu não conhecia, de uma fronteira com a densidade de ocupaçáo milenar - coisa inédita para uma brasileira cujo país há pouco completou meio milênio de idade - mas que, no entanto, naquela ocasião eu ainda tinha viva em minha memória minha experiência de vida em uma fronteira brasileira carregada de 
história, fascinantes eventos e de uma contemporaneidade extraordinária, pela sua convergência em muitos dos aspectos que caracterizam a vida contemporâneas - a tríplice fronteira Argentina, Brasil e Paraguai, vivida por mim em Foz do Iguaçu no Brasil e visitando, quase que cotidianamente Ciudad de Leste no Paraguai, uma zona franca, que como em todo lugar apodrece o subespaço onde se instala e Puerto Iguaçu, na Argentina, uma pequena e fascinante cidade do interior, organizada, limpa e sedutora.

Tudo isso, em Portugal, era um fato inédito para uma brasileira que tem uma compreensão territorial sempre continental e que toda fronteira só é tangível de avião ou após milhares de quilômetros de viagem...

Conversas interessantes tivemos sobre nossas concepçóes de território nacional, de pertencimento, de soberania, de escalas geográficas ...

Os quatro dias de reflexão e de debate sobre uma realidade tão ampla e complexa, como aquela fronteira entre Portugal e Espanha que visitamos, com camadas seculares de cultura e práticas vividas foram a mim apresentadas por Antonio Gama com um rigor disciplinar e crítico invejáveis. Semblante sério e rigoroso tanto para apresentar-me, em aulas particulares, a nascente do Douro, a terra natal de Pedro Álvares Cabral, nosso descobridor, quanto as experiências comunitárias das múltiplas aldeias que visitamos, algumas em franco processo de revitalização, na dimensão e escalas portuguesas, quase que incompreensíveis para uma geógrafa brasileira, acostumada a lidar e planejar cidades com no mínimo meio milhão de habitantes, ou São Paulo com quase 12 milhôes de habitantes!

Ríamos muito quando eu fazia esses comentários sobre escalas e pedia ao professor que tivesse um pouco de paciência para com essa professora que não era e nem nunca foi megalomaníaca, mas que estava habituada a lidar e trabalhar com outras escalas geográficas e gráficas...

Lembro-me perfeitamente que, no dia seguinte, quando tomávamos o café da manhã no Hotel da Guarda, grudado para meu espanto em uma muralha da cidade, António Gama me presenteia com uma minúscula rosa de miolo de páo que acabara de produzir com suas mãos talentosas, ao que entendi, dizendo-me sobre suas escalas de trabalho.... Aí está ela, como relíquia, em minha casa ... 


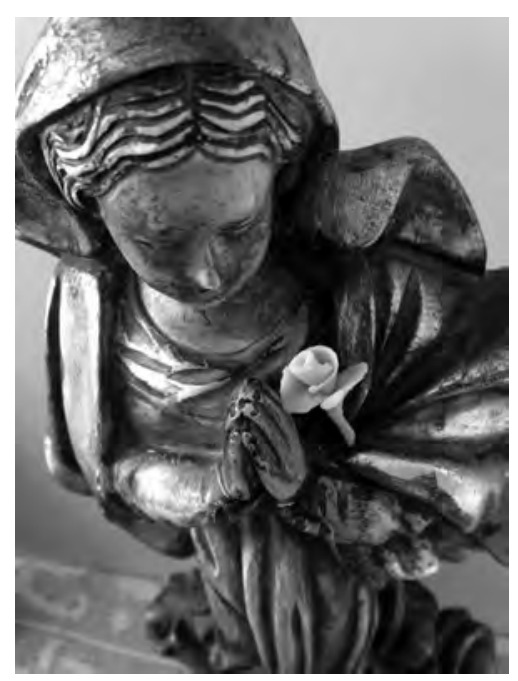

Foto 1

Autoria de Maria Adélia de Souza. Agosto, 2015. Campinas, SP.

Demos boas rizadas conversando sobre as dimensôes das coisas geográficas entre Portugal e Brasil...

Mas quando se tratava de intensidades históricas e seus testemunhos... eu apresentava a imensidão das placas do cambriano brasileiro, de nossa formação geológica. A única coisa que tinha para historicamente poder competir, minimamente com Portugal... Até então eu não havia conversado com meus colegas da Geografia Física de Coimbra, claro!

Sobre os temas do Curso trazidos à baila todo o tempo e no trabalho de campo, conversamos muito sobre Espaços de fronteira: paisagens e patrimônios; Espaços de fronteira: mobilidades e coesão; Territórios de esperança: iniciativas de desenvolvimento em contextos rurais e urbanos; Cooperação e diálogos lusófonos: velhos problemas, novas soluçóes, quando pude usufruir de aulas e explicações privilegiadas de Antônio Gama durante o percurso feito no campo. Inclusive sobre suas explicações sobre a magnífica paisagem que vislumbrávamos do alto da Serra da Estrela, toda desnuda e que eu havia conhecido em um inverno rigoroso, muitos anos antes.... E também sobre a origem e processos de produção de seus famosos e deliciosos queijos... 
Nosso trabalho de campo realizado sobre as Rotas Ibéricas, percorridas segundo o lema andar, ver e conhecer, sobre o qual eu havia tido noticias de sua intensidade, graças ao esforço e enorme dedicaçáo de seus professores líderes, com referência especial a Valentin Cabero tido como incansável e infatigável, Rui Jacinto como um disciplinador gentil e Antônio Gama como um pesquisador de campo obcecado. Náo preciso insistir no clima de aprendizagem e cordialidade que perdurou o tempo todo, alimentado pelo interesse e amizade de todos os colegas participantes, como eu. Durante toda viagem pudemos aprender e sentir com esses grandes professores as diferentes formas que as paisagens e os patrimônios assumem na área fronteiriça entre Portugal e Espanha.

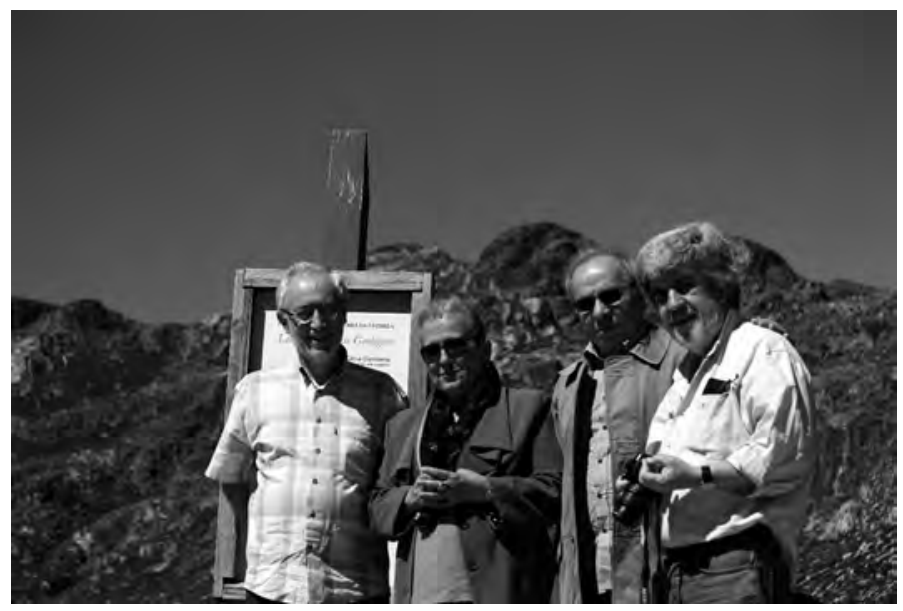

Foto 2

Autoria de Josué Viegas (junho 2014).

Da esquerda para a direita: Rui Jacinto, Maria Adélia de Souza, Messias Modesto Passos e António Gama. Ao fundo, Serra da Estrela.

Pela convergência de interesses na pesquisa geográfica, as conversas com Gama se dirigiram, como dito anteriormente, para a epistemologia da geografia, aos estudos da urbanização, do urbano e da cidade e a nova dimensão que nossos estudos precisaram tomar referente as características do mundo de hoje qual seja o cotidiano, a relação espaço-tempo e, por conseguinte, a grande novidade civilizatória constituída pela sociedade do ócio que se avizinha. 
Voltando ao Brasil fui tomar contato mais demorado com seus textos, pois francófila como fui no passado, deixei de lado, depois de Orlando Ribeiro, leitura obrigatória em meu curso de graduação, as obras dos colegas portugueses que agora retomei com enorme prazer e fonte de aprendizado.

De Gama, encantei-me com alguns deles. Fundamentos para uma Geografia do Tempo Livre (1992) e Notas para uma Geografia do Tempo Livre (1988), primorosa interpretação geográfica de um tema complexo, novo para a Geografia pela dimensão de tempo que lhe conforma. Gama exibe nesses textos erudição, audácia intelectual e espírito crítico sensível e de uma elegância acadêmica invejáveis!

Gama se interessou muito e me colocou muitas questôes sobre a Geografia Nova. Com curiosidade acadêmica ouviu-me explanar que lidávamos com um conceito de espaço geográfico compreendido não como um palco, onde as coisas e a vida acontecem e são colocadas, localizadas, mas como um conceito abstrato, uma instância social, "um indissociável e contraditório sistema de objetos e açôes”, conforme sugestão de definição feita por Milton Santos.

Expliquei-lhe sobre a genialidade de Milton Santos que, ao aproximar-se de Sartre, trazia-nos a importante reflexão e definição atualizada sobre TERRITÓRIO, avançando aquilo que ainda está confuso e que foi ultrapassado em relação ao seu uso na Geopolítica, pelas dinâmicas do mundo: o território apenas como definição do Estado nação ou, concepção e limite político administrativo de um país. Mas Milton Santos propóe o conceito de território praticado, usado como sinônimo de existência histórica, diferenciando-se do espaço geográfico, a instância social à qual nos referimos acima. E, também, ao sugerir-nos que o território dos cidadãos, o território normado, não é o mesmo das empresas, o território como recurso, o território como norma.

Para a pessoa comum, o território é abrigo, direito de uso! Portanto, a obra de Milton, no desenvolvimento desse conceito não nos permite aceitar os "sem" território: sem casa, sem teto, sem-terra, sem abrigo. O território assim, para o ser humano é condição de existência! Por isso ele precisa ser entendido e operacionalizado pelos métodos de pesquisa, como um fato político: usar o território é um direito ainda a ser conquistado pela maioria 
da população do planeta, ao menos no ocidente, pelo entrave trazido pela propriedade privada da terra...

Mas o território das empresas, além de viabilizar também a sua existência pelo uso, é considerado um recurso. Não é sem razáo que, para viabilizar a instalação de empresas, os municípios brasileiros ao menos, doam a elas (particulares que são) terras públicas e isentam do pagamento de impostos e taxas, anos a fio, o que não fazem para os cidadãos miseráveis e que vivem nas ruas...

Idiossincrasias do modo de viver que temos escolhido e que se confunde com o modo de viver das empresas...

Esta é minha leitura de um pedacinho da obra de Milton Santos, conversando com Antonio Gama enquanto percorríamos aldeias lindas, com arquiteturas totalmente estranhas aos brasileiros, mas vazias, assustadoras pelo seu silêncio e falta de vida humana, ali expressa apenas pelo trabalho morto realizado na produção daquelas paisagens, em tempos imemoriáveis...

É claro que, a partir dessas "prosas", Antonio Gama exibia sua erudição geográfica e histórica, apresentando-me seu país com um entusiasmo quase infantil, como um grande mestre que era e que, infelizmente, eu apenas acabara de conhecer, pessoalmente...

A Geografia portuguesa sempre nos ofereceu e nos oferece até hoje, grandes mestres!

Revelei a ele minha preocupaçáo com a crise urbana, que estava procurando compreender através da chegada daquilo que alguns pesquisadores e pensadores já estavam anunciando, mas que era difícil de ser imaginada em um país como o Brasil, onde o trabalho exaustivo e até escravo fazia parte intrínseca da nossa vida e nossa subsistência: a civilizaçáo ou sociedade do ócio. E, eis que ele me anuncia seu livro que saíra em 2008 (estávamos em 2014!!!) intitulado Lazer: da libertação do tempo à conquista das práticas!

Foi nesse momento que nos encontrámos no mesmo campo de interesse: a Geografia e o futuro das cidades, que certamente determinará o fim deste modo civilizatório que já mostra sinais de exaustấo... A conversa entấo passa a se desenvolver sobre nossas respectivas pesquisas, sobre autores com os quais interagimos, enfim uma conversa bonita, onde pude usufruir da erudição de 
meu colega, uma profícua relação acadêmica que começava a se fundar... abortada pela finitude da vida.

Como discutir a inevitabilidade da sociedade do ócio que ai está, em um país carente de tanta coisa como os nossos: o Brasil com sua juventude e correria para chegar com dignidade ao século xxi e Portugal, com sua proximidade dos melhores, oferecendo seus filhos, outrora como mão de obra para a construção civil no processo de reconstrução do pós II Guerra e hoje, cabeças pensantes que buscam horizontes e terrenos mais confortáveis e férteis para prosperar material e intelectualmente, diante das exigências do mundo novo em que vivemos e que conhece um processo de aceleração permanente do tempo.

Não tive o privilégio, ainda, de conhecer toda obra de Antonio Gama. Mas naquilo que nos aproximava intelectualmente, especialmente vinculado à "geografia urbana” e à sociedade do ócio pude refletir sobre alguns de seus textos.

Um deles, uma joia de reflexão, singela, firme e profunda como seu autor intitulada Fundamentos para uma Geografia do Tempo Livre (19921 e 2008), onde o autor revela seu rigor e sensibilidade, além da convergência em suas preocupaçóes e descobertas com a obra de Milton Santos em sua Geografia Nova.

Vejamos! Gama, nesse texto, assevera que "compreender a sociedade é também compreender como a imbricação do tempo e da duração geram as configuraçóes espaciais, ou melhor, as combinaçôes espaço-temporais. "Iniciei com Gama, no ônibus do nosso campo sobre o qual discorri acima, uma discussão epistemológica que prometia alongar-se e aprofundar-se: a diferença que faço, com relação a ele e a Milton Santos, distinguindo os conceitos de espaço geográfico e território.

Já Milton Santos (1994: 40), pouco tempo depois de Gama nos provoca, indo na mesma direção, alertando para a indissociabilidade entre espaço/ tempo: "Vemos com frequência entre os geógrafos a repetição da ideia de Paul Virillo (1984), para quem o espaço terminou, e só existe o tempo. Que

\footnotetext{
${ }^{1}$ Este texto tornado público em 1992. "Foi adaptado do texto com o mesmo nome, publicado nos Cadernos de Geografia, 7, 1988. Este texto é uma versão preliminar e parcial de um trabalho mais amplo "O Espaço, o tempo e o ócio", redigido no âmbito de um programa de investigação da linha de acção EPRU do C.E.G, de Lisboa. A Jorge Gaspar e João Ferrão agradeço as sugestôes que deram para sua elaboração.” (António Gama).
} 
fazer com essa metáfora, na medida em que nossa matéria prima é o espaço banal e este náo se extinguiu com a aceleraçáo contemporânea, mas apenas mudou de qualidade?"

Aceito a sugestáo de Milton Santos, quando em sua obra propóe que o espaço geográfico seja considerado uma instância social (tema que tristemente apenas comecei a discutir com Antonio Gama, pois é conceitual e epistemologicamente central na nossa perspectiva de trabalho). Isso vai revolucionar a perspectiva epistemológica da Geografia e abrir-lhe um campo necessário de diálogo interdisciplinar.

Mas, uso o conceito de território náo como sinônimo de espaço como propôs meu amigo-mestre Milton Santos, mas como uma historicização do espaço geográfico, conceito que para ser usado precisa ser acompanhado da categoria analítica proposta por meu amigo de "formaçáo socioespacial", ou seja, a necessidade de juntar à proposição de Marx de FES - Formação Econômica e Social, o espaço geográfico, como instância. Exatamente por isso, por ser histórico é que o conceito de território é essencial aos estudos geográficos, pois nos conduz à interpretação das paisagens historicamente produzidas, sempre.

O território, portanto, só existe, como nos ensina Milton Santos, quando usado, praticado. E essa prática se funda nas relaçóes sociais, alertando-nos pela condição político-econômica do uso, o que retira, definitivamente da Geografia, a sua condição de "descritora de paisagens", apenas. Descrever é referir-se ao existente, logo ao passado como forma visível. Mas hoje a geografia tem também âncora no futuro...

Tratam-se, portanto, o espaço geográfico e o território usado, de uma condição essencial da existência e, aí está outra conversa que começamos a ter - com o privilégio que eu estava tendo de poder falar sobre filosofia e geografia com um excelente interlocutor - sobre Sartre e o existencialismo que muito influenciou Milton e a mim, que tive o privilégio de assistir seus cursos em Paris, quando jovem doutoranda lá pelos idos de 1960 adentrando 1970.

Verifiquei lendo mais alguns textos de Antônio Gama que cito na bibliografia, em que medida foi um grande geógrafo elaborador de teorias e operacionalizador de métodos de pesquisa. Seu texto "Urbanização Difusa e Territorialidade Local", 
vê-se o pensador da urbanização e em "Notas para uma Geografia do Tempo livre", essa busca de operacionalização do método, a busca de tornar a teoria mais palpável para a aproximação e compreensão da realidade concreta.

Ao terminar estas reflexôes simples que faço em memória de um grande geógrafo, entristeço-me ao pensar o quanto teria sido importante continuar a conversar com Gama sobre a Geografia Nova, aprimorar o precioso legado deixado por Milton Santos, com essa interlocuçáo primorosa, rigorosa e competente que pude ter, por apenas 3 dias em toda nossa existência...

Coisas da vida... e da morte! Mas totalmente superadas pela lembrança e pela saudade, que é maior que ela.

António Gama, até sempre!

\section{Bibliografia}

Jacinto, Rui et al. (2015). António Gama Mendes: um geógrafo inquieto, um heterodoxo inconformado. Finisterra, Lisboa, n. ${ }^{\circ}$ 99, pp. 163-167.

Santos, Norberto Pinto dos \& Gama, António (2008). Lazer: da libertação do tempo à conquista das práticas. Editora: Imprensa da Universidade de Coimbra. 271 p.

Gama, António (1992). Urbanização Difusa e Territorialidade Local. Revista Crítica de Ciências Sociais. Coimbra, n. ${ }^{\circ}$ 34, pp. 161-172.

Gama, António (1994). As capitais no discurso geográfico. Penélope Fazer e Desfazer a História. Publicação Quadrimestral, n.o 13, pp. 9-21.

Gama, António (2008). Fundamentos para uma Geografia do tempo livre. In Norberto Pinto dos Santos e António Gama, Lazer: da libertação do tempo à conquista das práticas. Coimbra: Imprensa da Universidade de Coimbra, pp. 85-106.

Gama, António (2008). Notas para uma Geografia do Tempo livre. In Norberto Pinto dos Santos e António Gama, Lazer: da libertaçâo do tempo à conquista das práticas. Coimbra: Imprensa da Universidade de Coimbra, pp. 17-28.

Santos, Milton (1994). Técnica espaço tempo - globalização e meio técnico-cientifico informacional. São Paulo: Editora Hucitec. 